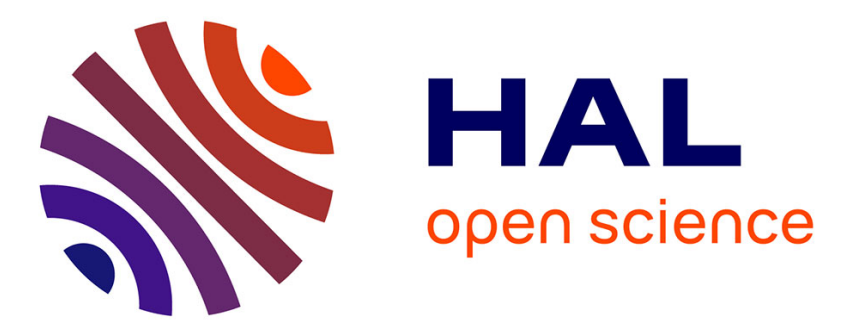

\title{
Excited-State Proton Transfer in Oxyluciferin and Its Analogues
}

Pauline Gosset, Gregory Taupier, Olivier Cregut, Johanna Brazard, Yves

Mely, Kokou Dodzi Dorkenoo, Jérémie Léonard, Pascal Didier

\section{- To cite this version:}

Pauline Gosset, Gregory Taupier, Olivier Cregut, Johanna Brazard, Yves Mely, et al.. Excited-State Proton Transfer in Oxyluciferin and Its Analogues. Journal of Physical Chemistry Letters, 2020, 11 (9), pp.3653-3659. 10.1021/acs.jpclett.0c00839 . hal-03034904

\section{HAL Id: hal-03034904 https://hal.science/hal-03034904}

Submitted on 7 Dec 2020

HAL is a multi-disciplinary open access archive for the deposit and dissemination of scientific research documents, whether they are published or not. The documents may come from teaching and research institutions in France or abroad, or from public or private research centers.
L'archive ouverte pluridisciplinaire HAL, est destinée au dépôt et à la diffusion de documents scientifiques de niveau recherche, publiés ou non, émanant des établissements d'enseignement et de recherche français ou étrangers, des laboratoires publics ou privés. 


\title{
Excited-State Proton Transfer in Oxyluciferin and its Analogues
}

\author{
Pauline Gosset $^{a, b}$, Grégory Taupier ${ }^{a}$, Olivier Crégut ${ }^{a}$, Johanna Brazard ${ }^{a}$, Yves \\ Mély $^{b}$, Kokou-Dodzi Dorkenoo ${ }^{a}$, Jérémie Léonard ${ }^{a, *}$, Pascal Didier ${ }^{b, *}$ \\ aIPCMS, Département d'Optique ultrarapide et de Nanophotonique (DON) UMR 7504 CNRS \\ 23 rue du Loess BP 43, 67034, STRASBOURG Cedex 2, France \\ ${ }^{b}$ Laboratoire de Bioimagerie et Pathologies, UMR 7021 CNRS, Université de Strasbourg, \\ 67000 STRASBOURG, France \\ *corresponding authors: jeremie.leonard@ipcms.unistra.fr and pascal.didier@unistra.fr
}

\begin{abstract}
One of the most characterized bioluminescent reactions involves the firefly luciferase that catalyzes the oxidation of the luciferin producing oxyluciferin in its first excited state. While relaxing to the ground state, oxyluciferin emits visible light with an emission maximum that can vary from green to red. Oxyluciferin exists under six different chemical forms resulting from a keto/enol tautomerization and the deprotonation of the phenol or enol moieties. The optical properties of each chemical form have been recently characterized by the investigations of a variety of oxyluciferin derivatives, indicating unresolved excited-state proton transfer (ESPT) reactions. In this work, femtosecond pump-probe spectroscopy and picosecond-resolved fluorescence are used to investigate the picosecond kinetics of the ESPT reactions and demonstrate the excited state keto to enol conversion of oxyluciferin and its derivatives in aqueous buffer as a function of $\mathrm{pH}$. A comprehensive photophysical scheme is provided describing the complex luminescence pathways of oxyluciferin in protic solution.
\end{abstract}

\section{TOC Graphic}

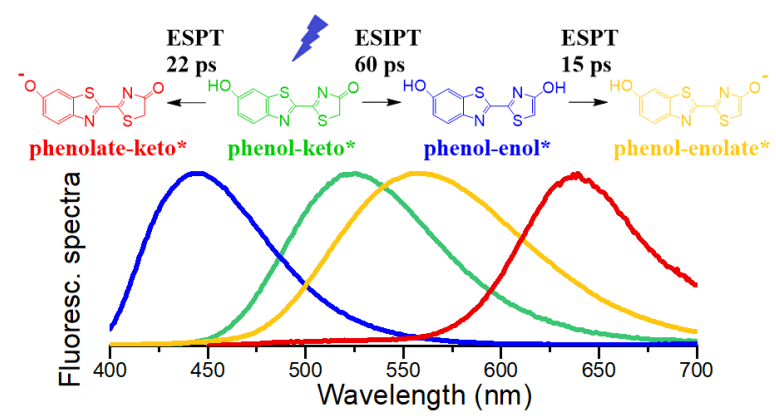

Bioluminescence refers to the fascinating phenomenon of natural conversion of chemical energy into light ${ }^{1}$ by living organisms. It is observed in the deep sea from sharks ${ }^{2}$, dinoflagellates $^{3,4}$, jellyfishes ${ }^{3}$ or on earth from bacteria ${ }^{3,5}$ or worms ${ }^{6}$. Up to now, firefly is the most studied bioluminescent organism due to the high efficiency of its light-emissive enzymatic 
reaction ${ }^{7}$. The light is emitted through the luciferase-catalyzed oxidation of D-luciferin resulting in the formation of oxyluciferin $\left(\mathrm{OxyLH}_{2}\right)$ in its first singlet excited state $\left(\mathrm{S}_{1}\right)$, which then decays radiatively to the ground state ${ }^{8-11}$. Due to its high quantum yield and the absence of autofluorescence (no photo-excitation) that enable a high signal-to-noise ratio, the luciferin/luciferase complex is very popular and widely used as a luminescent probe ${ }^{11,12}$ for bioassays $^{13-15}$ and for in vivo and in vitro bioimaging ${ }^{16-20}$.

Natural bioluminescence wavelengths are observed to vary from green to red ${ }^{1,21}$. Due to its increasing number of applications, it is essential to understand the origin of the color modulation which depends on several factors such as temperature, $\mathrm{pH}$ or nature of the luciferase enzyme ${ }^{1,22-24}$. OxyLH $\mathrm{H}_{2}$ can exist under six different chemical forms resulting from keto/enol tautomerization (see Scheme 1) and the deprotonation of the phenol and enol moieties ${ }^{25,26}$. The main obstacle to the understanding of the $\mathrm{OxyLH}_{2}$ fluorescence emission is the high complexity of its environment-sensitive photochemistry, which implies several ground-state equilibria and excited-state interconversions between various protonated/deprotonated and keto/enol forms. In addition, a major limiting experimental factor has long been related to the chemical synthesis of $\mathrm{OxyLH}_{2}$, its lability being due to the presence of both keto and enol forms in protic solution that permits a Mannich-type dimerization ${ }^{27}$. For these reasons, most spectroscopic investigations were performed on luciferin in solution in the absence of the enzyme ${ }^{28-32}$ or only recently on $\mathrm{OxyLH}_{2}$ and model compounds where excited state proton transfer (ESPT) or ketoenol tautomerization are blocked. The steady-state optical properties of these derivatives have been extensively investigated both theoretically ${ }^{26,33-41}$ and experimentally ${ }^{31,42,43}$ allowing for instance to determine the relative concentrations of each chemical form as a function of $\mathrm{pH}^{31,42}$. We recently characterized the $\mathrm{pH}$ dependence of oxyluciferin photophysics by using the 5,5Cpr-OxyLH $(\mathrm{Cpr}=($ spiro $)$ cyclopropyl $)$ and the 6'-Me-5,5-Cpr-OxyL to mimic the keto species and 4-MeOxyLH, 6'-MeOxyLH or 4.6'- DMeOxyL $^{31}$ as enol analogues. These experiments 
allowed us to propose a complete model to account for the photoluminescence cycle of $\mathrm{OxyLH}_{2}$ in aqueous solution. However, the limited temporal resolution of these experiments prevented the characterization of the sub-50 ps dynamics associated to excited state reactions (ESPT and tautomerization). The majority of the ultrafast spectroscopy investigations to characterize the ESPT of D-luciferin, and more recently of $\mathrm{OxyLH}_{2}$ in solution were performed by the group of D. Huppert ${ }^{44-47}$ by time-resolved fluorescence up-conversion or photon counting techniques. Presiado I. et al. work with D-luciferin to mimic the keto form and dehydroluciferin to model the enol form ${ }^{44}$, other groups use the 5,5-dimethyloxyluciferin to inhibit the keto-enol tautomerization $^{6,11}$. Erez et al. characterized the excited-state intermolecular proton transfer using fluorescence up-conversion and determined the ESPT rate constant in water $\left(3.0 \times 10^{10} \mathrm{~s}^{-}\right.$ $\left.{ }^{1}\right)$. They were however not able to disentangle the contributions of the various forms of $\mathrm{OxyLH}_{2}$ which were since then shown to coexist in their experimental conditions $(\mathrm{pH}=6)^{31}$. The only transient absorption experiment we are aware of was carried out on luciferin, with ps time resolution $^{48}$.<smiles>Cc1csc(-c2nc3ccc(O)cc3s2)n1</smiles>
phenol-enol<smiles>[O-]c1ccc2nc(-c3nc(O)cs3)sc2c1</smiles>
phenolate-enol<smiles>O=C1CSC(c2nc3ccc(O)cc3s2)=N1</smiles>
phenol-keto<smiles>O=C1CSC(c2nc3ccc([O-])cc3s2)=N1</smiles>
phenolate-keto<smiles>[O-]c1csc(-c2nc3ccc(O)cc3s2)n1</smiles>
phenol-enolate<smiles>[O-]c1ccc2nc(-c3nc([O-])cs3)sc2c1</smiles>
phenolate-enolate

Scheme 1: Possible ground-state chemical forms of $\mathrm{OxyLH}_{2}$ in solution.

The above mentioned excited state reaction is also supported by theoretical calculations performed to model the proton transfer for $\mathrm{OxyLH}_{2}$ and its analogues ${ }^{49-52}$. Another key step of the $\mathrm{OxyLH}_{2}$ photophysics relies on the keto-enol tautomerization. Indeed, according to the wellestablished enzymatic reaction model, the bioluminescence emitter is created in its keto form 
which can, during its excited state lifetime, undergo partial enolization and deprotonation. Experiments performed by Naumov et al. using oxyluciferin analogues evidenced that in a nonpolar and basic environment the keto form in the excited state can tautomerize into the enol form, which subsequently undergoes excited state proton transfer to produce the enolate ion ${ }^{26,32}$. These authors were however unable to determine the time scale of the keto-enol conversion.

To decipher the ps kinetics associated to the conversion between the $\mathrm{OxyLH}_{2}$ species, we report here on femtosecond transient absorption (TA) and nanosecond fluorescence decay measurements (see experimental details in the SI) performed on $\mathrm{OxyLH}_{2}$ and its analogues (Scheme 2) in acidic $(\mathrm{pH}=5)$ and basic $(\mathrm{pH}=11)$ aqueous buffer solutions for which it is possible to avoid a mixture between protonated and deprotonated forms in the ground state. Still, the ground state keto-enol tautomerism results in the coexistence of both phenol-keto (Scheme 2 a) and phenol-enol (Scheme 2b) tautomers for the $\mathrm{OxyLH}_{2}$ at $\mathrm{pH}=5$ as previously reported..$^{31}$

a)

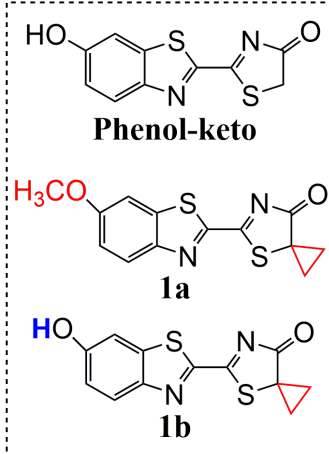

b)

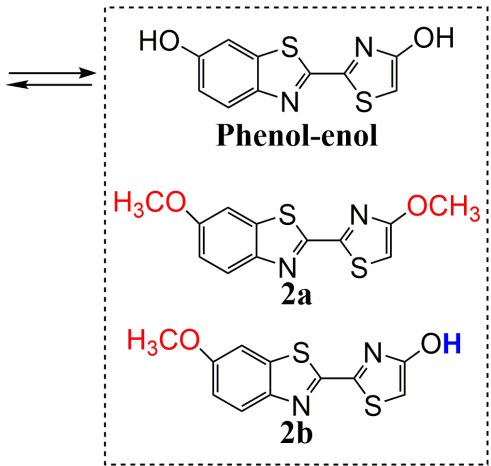

Scheme 2: Model compounds used to mimic various forms of $\mathrm{OxyLH}_{2}$.

Hence, we first studied compounds $\mathbf{1 a}$ and $\mathbf{1 b}$ which mimic the keto species, since the Cpr cycle prevents the conversion to the enol form (see Scheme1). In 1a, the phenol form is "locked" since the hydroxyl group is replaced by a methoxy substituent (red) that precludes deprotonation in $\mathrm{S}_{0}$ and in $\mathrm{S}_{1}$ (ESPT is no longer possible). Conversely, $\mathbf{1 b}$ is used to investigate 
the phenol-phenolate conversion of the keto form, in both $S_{0}$ and $S_{1}$. Figure 1 displays the TA data obtained for these compounds as a function of $\mathrm{pH}$.
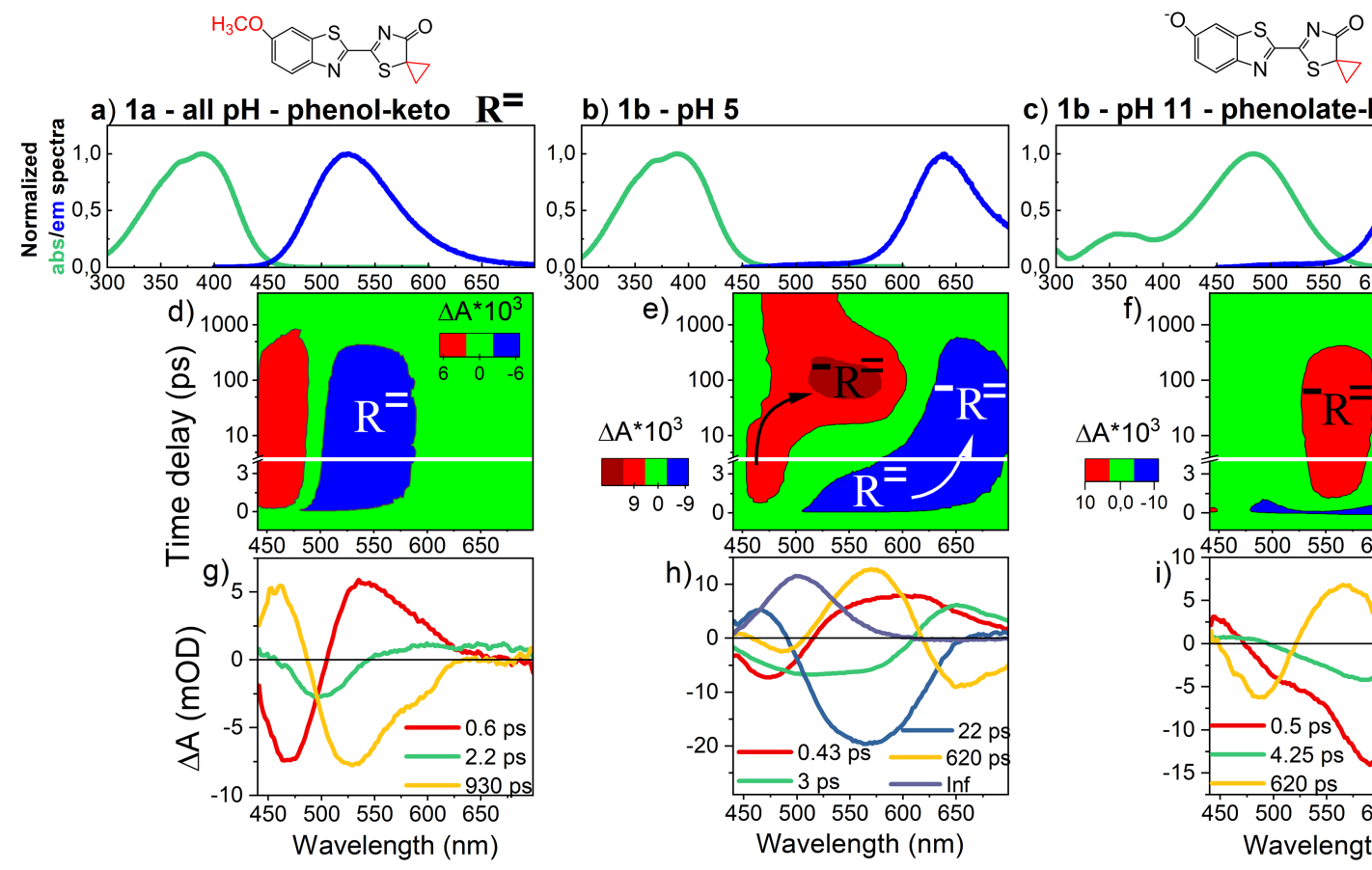

c) $1 \mathrm{~b}-\mathrm{pH} 11$ - phenolate-keto ${ }^{-} \mathrm{R}=$

Figure 1 : Excited-state signatures of the phenol-keto analogues. TA spectroscopy of $1 \mathrm{a}$ for all $\mathrm{pH}$ values (right) and $\mathbf{1 b}$ at $\mathrm{pH}=5$ (middle) and $\mathrm{pH}=11$ (left). (a), (b) and (c) are steady-state absorption (green) and emission (blue) spectra, (d), (e) and (f) are 2D maps, false-color representations of the transient absorption $(\Delta \mathrm{A})$ signal as a function of probe wavelength and pump-probe delay. Positive (red) and negative (blue) contributions are Excited State Absorptions (ESA) and Stimulated emissions (SE), respectively. (g), (h) and (i) are the Decay Associated Spectra (DAS) obtained from global analysis (see SI for details).

The absorption and emission maxima wavelengths of 1a are $388 \mathrm{~nm}$ and $525 \mathrm{~nm}$ respectively, independent of the $\mathrm{pH}$ value (Figure 1a). At $\mathrm{pH}=5, \mathbf{1 b}$ is protonated and its absorption spectrum is the same as 1a, characterizing the phenol-keto form. At $\mathrm{pH}=11, \mathbf{1 b}$ deprotonated (i.e. phenolate-keto) and its absorption maximum is shifted to $482 \mathrm{~nm}$. For both $\mathrm{pH}$ values, the emission spectrum of $\mathbf{1 b}$ is the same, centered at $640 \mathrm{~nm}$, indicating that the same emissive state is observed.

For 1a, two contributions are clearly apparent in the TA data (Figure 1d), a positive signal (in red) at $460 \mathrm{~nm}$ associated to an Excited-State Absorption (ESA) and a negative signal (in blue) at $525 \mathrm{~nm}$ corresponding to Stimulated Emission (SE) band that matches the steady- 
state emission spectrum of the phenol-keto form later denoted $\mathbf{R}=$. For $\mathbf{1 b}$ at $\mathrm{pH}=5$, the early ESA and SE bands at $470 \mathrm{~nm}$ and $525 \mathrm{~nm}$ respectively, are associated to the same $\mathrm{S}_{1 \text {. }}$ signature of the phenol-keto form $\left(\mathbf{R}^{=}\right)$. After a few picoseconds, these bands undergo a red-shift to 550 $\mathrm{nm}$ and $640 \mathrm{~nm}$ respectively, which correspond to the $S_{1}$ signature of the phenolate-keto form $\left(-\mathbf{R}^{=}\right)$form as evidenced by the TA data obtained at $\mathrm{pH}=11$ in Figure 1f. We conclude that the TA data for $\mathbf{1 b}$ at $\mathrm{pH}=5$, reveal the deprotonation of the phenol-keto form in $\mathrm{S}_{1}$, namely an ESPT reaction. At long time delays at $\mathrm{pH}=5$ (Figure 1e), a positive signal at $480 \mathrm{~nm}$ remains up to 4 ns (and beyond), after the decay of the two $-\mathbf{R}^{=} \mathrm{S}_{1}$ contributions. This long-lived signal corresponds to the absorption band of the deprotonated, ground-state photoproduct.

The results of the global analysis of the TA data (see methods in SI) are reported Figure $1 \mathrm{~g}, \mathrm{~h}, \mathrm{i}$. The long time constants (yellow) were obtained from fluorescence decay measurements and fixed for the TA analysis. The short time constants of $0.6 \mathrm{ps}$ and $2.2 \mathrm{ps}$ for $1 \mathbf{a}, 0.43 \mathrm{ps}$ for $\mathbf{1 b}$ at $\mathrm{pH}=5$, and $0.5 \mathrm{ps}$ and $4.25 \mathrm{ps}$ for $\mathbf{1 b}$ at $\mathrm{pH}=11$ characterize spectral relaxations likely due to vibrational and solvent relaxation. The 3 -ps time constant for $\mathbf{1 b}$ at $\mathrm{pH}=5$, is a time scale on which we may expect further vibrational and solvent relaxation in line with the 2.2-ps DAS obtained for 1a, but on this time scale, the rise of the $640 \mathrm{~nm} \mathrm{SE}$ band of the deprotonated form $\left(-\mathbf{R}^{=}\right)$is clearly observed. On the 22 ps time constant, we observe the complete decay of the initial ESA band at $470 \mathrm{~nm}$, as well as the decay of the initial SE and rise of the subsequent ESA both around $540-570 \mathrm{~nm}$. Hence, both the 3 ps and 22 ps time constants are associated to the ESPT reaction kinetics. The DAS associated to the infinite time constant is similar to the steady-state absorption spectrum measured at $\mathrm{pH}=11$, confirming its assignment to the deprotonated ground-state. Therefore, reprotonation of the ground-state is significantly slower than $4 \mathrm{~ns}$, which is the maximum accessible time delay in our TA experiment. 


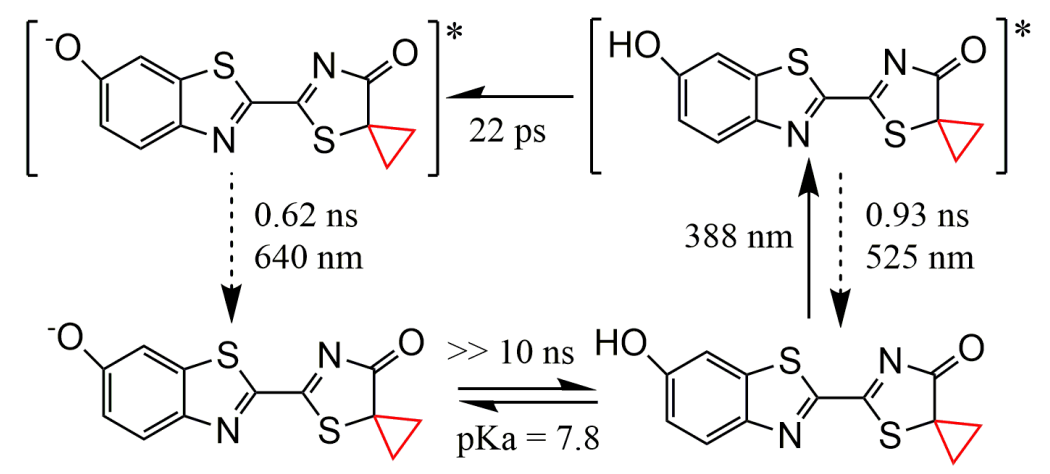

Scheme 3 : Photoluminescence pathway of the phenol-keto species.

Scheme 3 summarizes the photoluminescence pathway of the phenol-keto form and the characteristic time associated to the ESPT reaction from the phenol-keto to phenolate-keto form, as determined here by TA absorption spectroscopy.
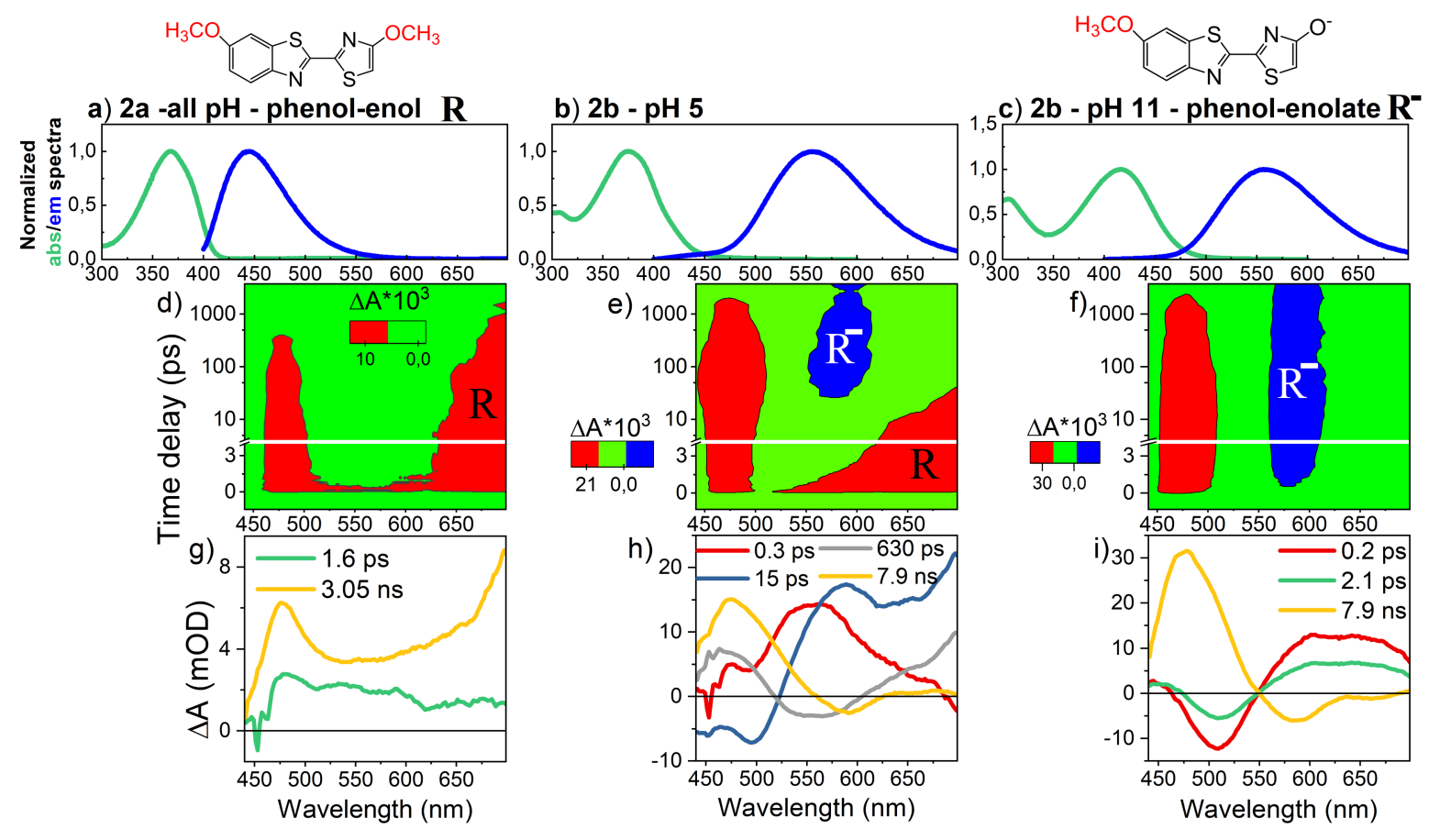

Figure 2 : Excited-state signatures of the phenol-enol analogues. TA spectroscopy of $2 \mathrm{a}$ for all $\mathrm{pH}$ values (right) and $\mathbf{2 b}$ at $\mathrm{pH}=5$ (middle) and $\mathrm{pH}=11$ (left). (a), (b) and (c) are steadystate absorption (green) and emission (blue) spectra, (d), (e) and (f) are 2D map of the transient absorption $(\Delta \mathrm{A})$ signal as a function of probe wavelength and pump-probe delay. Positive contributions (red) are the Excited State Absorption (ESA) and the negative contributions (blue) corresponds to the Stimulated Emission (SE). (g), (h) and (i) are the DAS obtained after the global analysis.

We next report on the excited-state dynamics of $\mathbf{2 a}$ and $\mathbf{2 b}$. For $\mathbf{2 a}$, where two methoxy groups prevent deprotonation in $\mathrm{S}_{0}$ or $\mathrm{S}_{1}$, the absorption and emission maxima are at $367 \mathrm{~nm}$ 
and $445 \mathrm{~nm}$, respectively (Figure 2a). For $\mathbf{2 b}$, only one methoxy group is present to lock the "phenol" moity - i.e. methoxyphenyl - such that the enol-keto conversion may occur. At $\mathrm{pH}=5$, the absorption spectrum is maximum at $367 \mathrm{~nm}$ and corresponds to a mixture of both tautomers which indeed coexist at equilibrium in the ground state. Upon excitation at 400nm, the fraction of light absorbed by the enol and keto forms are $66 \%$ and and $33 \%$, respectively. ${ }^{42}$ Only the enol moiety can undergo an ESPT. At $\mathrm{pH}=11$ instead, the enolate form is pure in the ground state with an absorption band $(415 \mathrm{~nm})$ characterizing the phenol-enolate form. The $\mathbf{2 b}$ emission maximum is $555 \mathrm{~nm}$ for both $\mathrm{pH}$ values.

The TA spectra for $2 \mathbf{a}$ are characterized by two ESA bands centered at $475 \mathrm{~nm}$ and $675 \mathrm{~nm}$ (Figure 2d), the former one overcoming - and therefore masking - the SE signal expected in the same spectral range. The $675 \mathrm{~nm}$ ESA will next be used as a specific signature of the phenol-enol form in $\mathrm{S}_{1}$ and is denoted $\mathbf{R}$ hereafter. For $\mathbf{2 b}$ at $\mathrm{pH}=5$, the same two $\mathrm{ESA}$ bands as in 2a ( $\mathbf{R}$ signature) are observed at early times, and are replaced after several tens of ps by the $\mathrm{S}_{1}$ signatures $\mathrm{SE}$ of the phenol-enolate $\left(\mathbf{R}^{-}\right)$, observed at $\mathrm{pH}=11$ (Figure $\left.2 \mathrm{f}\right)$. We note here already, that since both tautomers are present in the ground state, we should also expect to observe in the $\mathbf{2 b}$ TA map the $\mathbf{R}^{=}$signature as illustrated in Figure 1d (remember that $\mathbf{2 b}$ cannot deprotonate on the phenol moiety, like 1a). However, while the $\mathrm{R}=$ signature is not easily identified by visual inspection of figure $2 \mathrm{e}$, it will clearly arise from its quantitative analysis and corresponding DAS as discussed below.

The DAS resulting from global analysis are displayed in Figure $2 \mathrm{~g}, \mathrm{~h}$ and i. Here again, the shortest time constants of 1.6 ps for $\mathbf{2 a}, 0.3$ ps for $\mathbf{2} \mathbf{b}$ at $\mathrm{pH}=5$ and $0.2 \mathrm{ps}$ and $2.1 \mathrm{ps}$ for $\mathbf{2} \mathbf{b}$ at $\mathrm{pH}=11$ are attributed to intramolecular and solvent relaxations, and the longest time constants (yellow) are those obtained from fluorescence decay measurements (Table S2). The remaining 15 ps and 630 ps components for $\mathbf{2 b}$ at $\mathrm{pH}=5$ are not present at $\mathrm{pH}=11$. The $15 \mathrm{ps}$ DAS is clearly associated to the phenol-enol to phenol-enolate ESPT, because its spectral shape reveals the 
decay of the $675 \mathrm{~nm}$ ESA band characterizing $\mathbf{R}$, and the rise of the $\mathbf{R}-\mathrm{SE}$ band around 580 nm. Finally, the 630 ps DAS (Figure 2h, grey vurve) displays - below 600nm - a spectral shape similar to that of the 930 ps DAS characterizing the decay of the phenol-keto $\left(\mathbf{R}^{=}\right)$signature as identified with 1a (Figure 1g), in full line with our expectations above since both tautomers are excited at $400 \mathrm{~nm}$.

This analysis is confirmed by time-resolved fluorescence spectroscopy of $\mathbf{2 b}$ at $\mathrm{pH}=5$, which also reveals a 630 ps lifetime - significantly different from the 930 ps one measured for 1a - together with a 7.9 ns time constant associated to the decay of the phenol-enolate form. As we will further argue below for the case of $\mathrm{OxyLH}_{2}$, we propose here that the decrease in the lifetime of the phenol-keto species in $\mathbf{2} \mathbf{b}$ with respect to $\mathbf{1 a}$ is due to the keto to enol conversion, which is an additional decay channel for $\mathbf{2} \mathbf{b}$, as compared to $\mathbf{1 a}$ where the cyclopropyl group prevents it. We thus infer the rate constant of the $S_{1}$ keto to enol conversion of $\mathbf{2} \mathbf{b}$ as being (2ns)${ }^{1}=(630 \mathrm{ps})^{-1}-(930 \mathrm{ps})^{-1}$. Scheme 4 summarizes the photoluminescence pathway accounting for the ESPT leading to the formation of the phenol-enolate form as well as the excited-state ketoenol conversion.

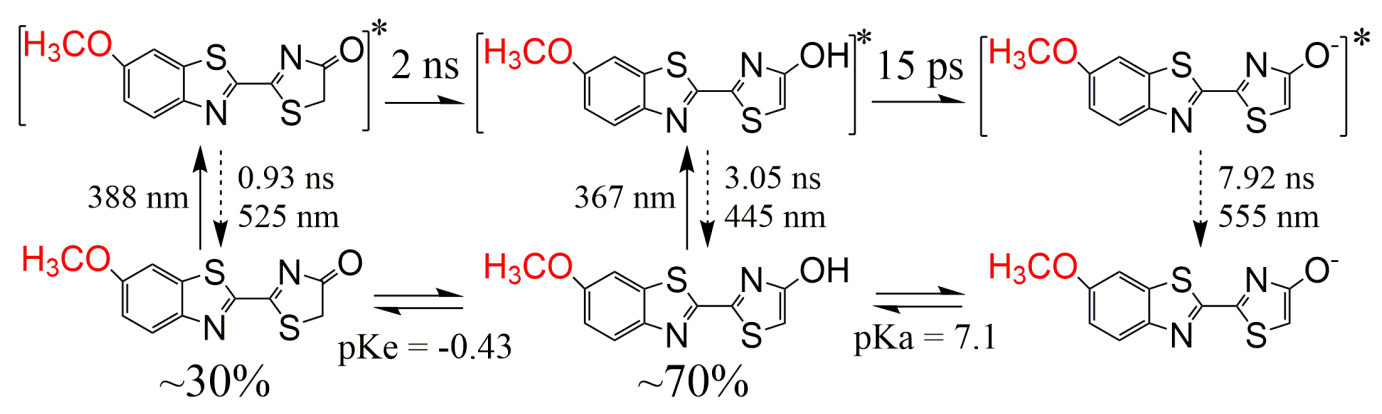

Scheme 4 : Photoluminescence pathway of the phenol-enol species 


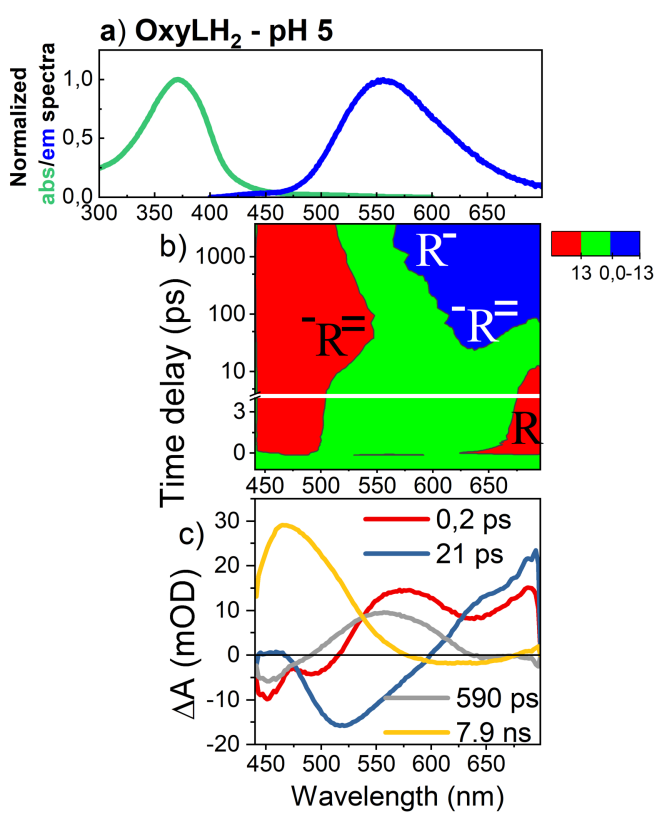

Figure 3: Excited-state signatures of $\mathrm{OxyLH}_{2}$ measured at pH 5. (a) Steady-state absorption (green) and emission (blue) spectra, (b) 2D map of the transient absorption ( $\Delta \mathrm{A}$ ) signal as a function of probe wavelength and pump-probe delay. Positive contributions (red) are the ESA and the negative contributions (blue) correspond to SE. (c) DAS obtained after global analysis.

After identifying the spectral signatures and kinetics of $\mathbf{1 a}$ and $\mathbf{2} \mathbf{b}$, we conclude this work by discussing the photoluminescence pathway of $\mathrm{OxyLH}_{2}$ at $\mathrm{pH}=5$. TA spectroscopy data are displayed in Figure 3. At $\mathrm{pH}=5, \mathrm{OxyLH}_{2}$ is a $30 \% / 70 \%$ keto/enol mixture, characterized by an absorption maximum at $371 \mathrm{~nm}$, and a dual emission spectrum with a dominating band centered at $555 \mathrm{~nm}$ and a weaker one at $450 \mathrm{~nm}$ (Figure 3a). Upon $400 \mathrm{~nm}$ excitation of both tautomers, the TA data (Figure $3 \mathrm{~b}$ ) reveals the $675 \mathrm{~nm}$ ESA band characterizing the $\mathrm{S}_{1}$ signature of the phenol-enol form $(\mathbf{R})$ at early time delays. On the few-10-ps time scale, this signature disappears to give rise to a red $(640 \mathrm{~nm}) \mathrm{SE}$ while the high energy ESA red-shifts from $475 \mathrm{~nm}$ to $\sim 520 \mathrm{~nm}$. This indicates the formation of phenolate-keto $\left(-\mathbf{R}^{=}\right)$form, as observed in Figure 1e, produced upon direct excitation of the phenol-keto form already present in $\mathrm{S}_{0}$. Finally, the SE band broadens down to below $600 \mathrm{~nm}$ on the few-100-ps time scale and remains long-lived, which is the signature identified for the phenol-enolate (R-, Figure 2e) formed via ESPT upon direct excitation of the phenol-enol form. 
The quantitative analysis of the TA data is reported in Figure $3 \mathrm{c}$. The longest lifetime of $7.9 \mathrm{~ns}$ was determined by TCSPC fluorescence spectroscopy. The spectral shape of the $7.9 \mathrm{~ns}$ DAS is thought to correspond to the sum of the phenol-enolate ESA (7.9 ns DAS in Figure 2i) and the ground state absorption of the phenolate-keto observed for $\mathbf{1 b}$ ("inf" DAS in Figure 2h). The 590 ps DAS has a spectral shape recalling the 630 ps DAS observed in Figure $1 \mathrm{~h}$ and is thus assigned to the phenolate-keto $\left(-\mathbf{R}^{=}\right)$decay. The 21 ps DAS component (Figure 3c) likely accounts for both ESPT reactions occurring on similar time scales. The shortest time constant (0.2 ps) and corresponding DAS are assigned to spectral relaxations due to intramolecular and/or solvent relaxations. Similarly to the experiments performed on compounds $\mathbf{1 b}$ and $\mathbf{2 b}$ in bsic conditions, the excited state dynamics of oxyluciferin at $\mathrm{pH}=11$ (Figure $\mathrm{S} 2$ ) is described by a single species displaying a fluorescence lifetime of $6.2 \mathrm{~ns}$ significantly different from the phenol-enolate lifetime $(7.9 \mathrm{~ns})$. This contribution is associated to the dianion OxyL ${ }^{2-}$ (i.e. phenolate-enolate) which was shown to be the only ground state species in basic condition ${ }^{31}$, and does not contribute to the photoluminescence pathway in acidic conditions.

We next wonder if the $S_{1}$ keto to enol conversion observed with $\mathbf{2} \mathbf{b}$ may also occur for $\mathrm{OxyLH}_{2}$ at $\mathrm{pH}$ 5. We were best able to address this question based on fluorescence spectroscopy after shifting the excitation wavelength to $430 \mathrm{~nm}$, where only the phenol-keto form absorbs in the initial tautomer mixture (Figure S3). The measured fluorescence decays and emission spectrum clearly evidence the contribution of both phenolate-keto and phenol-enolate forms (Figure S5), demonstrating the excited state phenol-keto to phenol-enol conversion. Both forms are also rapidly converted, through an ESPT reaction, into the phenolate-keto and phenolenolate anions, respectively. More precisely, the relative amplitudes associated to the decay components of the phenolate-keto (0.62 ns) and of the phenol-enolate (7.9 ns) - see Figure S5a - allow us to infer the phenol-keto to phenol-enol conversion rate $\mathrm{k} 1$, on the basis of the global photoluminescence Scheme 5 and corresponding rate equations solved numerically (see SI). 
Independently, the relative weight of both anion emission spectra in the OxyLH2 steady-state fluorescence (Figure S5b) can be analyzed (see SI) to infer k1 as well. Both the analyses of time-resolved and steady-state emission data reveal the same value of $\mathrm{k} 1=(60 \mathrm{ps})^{-1}$. All time constants associated to the kinetics of the complex photoluminescence pathway of $\mathrm{OxyLH}_{2}$ determined in this work are summarized in Scheme 5.

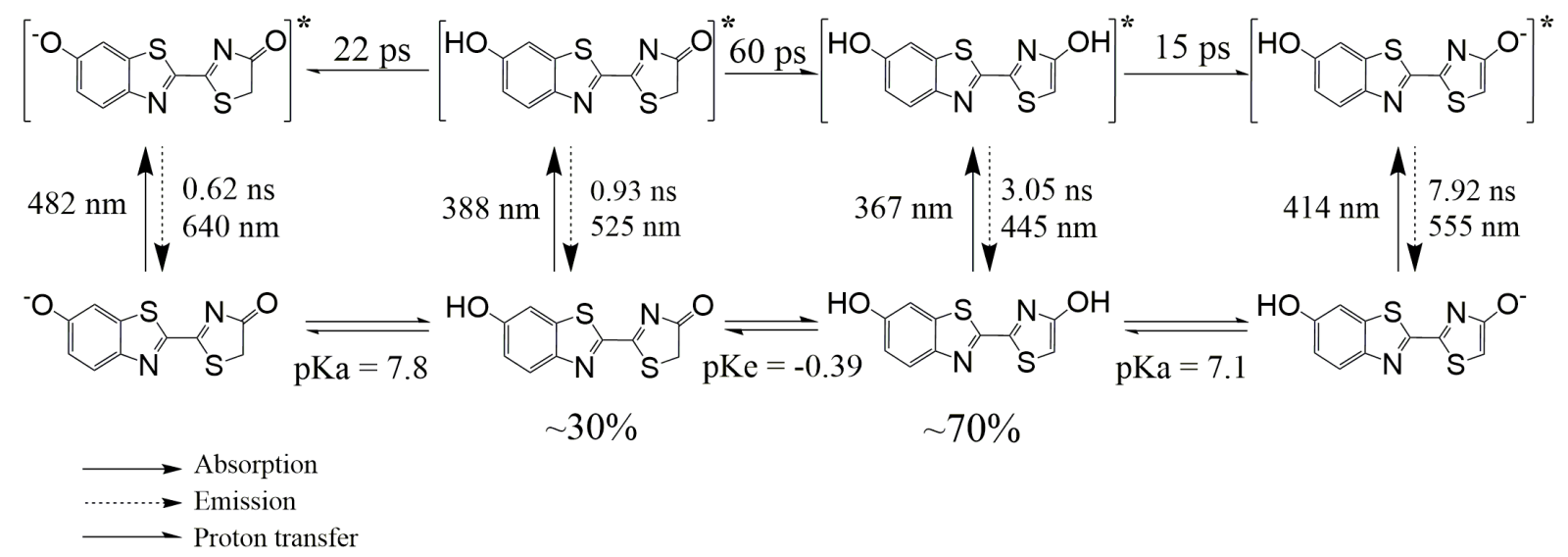

Scheme 5: Photoluminescence Pathways of Oxyluciferin in Aqueous Solution at pH 5

In conclusion, spectrally-resolved femtosecond transient absorption experiments and TCSPC fluorescence decay measurements were used to characterize the excited-state dynamics of OxyLH2 and its analogues as a function of the $\mathrm{pH}$ in water solution. With the help of derivatives where deprotonations or keto-enol tautomerization are blocked, it was possible to determine for the first time the characteristic time constants associated to the excited-state reactions. For the phenol-keto and phenol-enol model compounds, the measured ESPT time scales are on the order of 15-20 ps. Moreover, the DAS analysis performed on the model compounds allowed us to identify their specific $S_{1}$ spectral signatures. The results obtained with these compounds were used to interpret the dynamics observed on the natural emitter: $\mathrm{OxyLH}_{2}$. In particular, the characteristic spectral signatures of the model compounds were used to disentangle the contributions from the phenol-enol and phenol-keto forms in the complex photophysics of $\mathrm{OxyLH}_{2}$, including site-specific ESPT reactions and their kinetics. In addition, 
experiments with red-shifted excitation were performed to characterize the excited-state conversion of $\mathrm{OxyLH}_{2}$ from the phenol-keto to phenol-enol forms. All these results were used to fully unravel the complex photoluminescence pathways of $\mathrm{OxyLH}_{2}$ at $\mathrm{pH}=5$ by providing the excited-state reaction timescales (Scheme 5). Though these results do not directly apply to the photoreactivity within the luciferase active pocket, they demonstrate the role played by the $\mathrm{pH}$ on the excited-state photophysics, and the key role of specific hydrogen bonds between the chromophore and the protein binding pocket for controlling the bioluminescence spectrum via the tuning of excited- state proton transfer or tautomerism reaction kinetics. They also suggest that the same strategy could be used by incorporating these synthetic compounds in the natural binding pocket of Luciferase in order to unravel the photoluminescence mechanism of the oxyluciferin-luciferase complex. This work is in progress in our labs.

\section{Acknowledegments}

This work was supported by the Agence Nationale de la Recherche (BIOLUM ANR-16-CE290013).

\section{Supporting Information Available}

Experimental details; fluorescence decays and singular transient measured at $\mathrm{pH}=5$ and $\mathrm{pH}=11$; table containing all the measured lifetimes; description of the model used to determine the keto to enol excited state conversion rate.

\section{References}

(1) Seliger, H. H.; McElroy, W. D. The Colors Of Firefly Bioluminescence: Enzyme Configuration And Species Specificity. Proc. Natl. Acad. Sci. U. S. A. 1964, 52 (1), 75-81.

(2) Duchatelet, L.; Claes, J. M.; Mallefet, J. Embryonic Expression of Encephalopsin Supports Bioluminescence Perception in Lanternshark Photophores. Mar. Biol. 2019, 166 (21). https://doi.org/10.1007/s00227-019-3473-9.

(3) Woodland, J.; Gibson, H. Intermediates in the Bioluminescent Oxidation of Reduced Flavin Mononucleotide. J. Biol. Chem. 1963, 238 (7), 2537-2554.

(4) Lindström, J.; Grebner, W.; Rigby, K.; Selander, E. Effects of Predator Lipids on Dinoflagellate Defence Mechanisms - Increased Bioluminescence Capacity. Sci. Rep. 2017, 7 (13104). https://doi.org/10.1038/s41598-017-13293-4.

(5) Lee, J. Perspectives on Bioluminescence Mechanisms. Photochem. Photobiol. 2017, 93 (2), 389-404. https://doi.org/10.1111/php.12650. 
(6) Branchini, B. R.; Southworth, T. L.; Murtiashaw, M. H.; Magyar, R. A.; Gonzalez, S. A.; Ruggiero, M. C.; Stroh, J. G. An Alternative Mechanism of Bioluminescence Color Determination in Firefly Luciferase. Biochemistry 2004, 43 (23), 7255-7262. https://doi.org/10.1021/bi036175d.

(7) Ando, Y.; Niwa, K.; Yamada, N.; Enomoto, T.; Irie, T.; Kubota, H.; Ohmiya, Y.; Akiyama, H. Firefly Bioluminescence Quantum Yield and Colour Change by PH-Sensitive Green Emission. Nat. Photonics 2008, 2 (1), 44-47. https://doi.org/10.1038/nphoton.2007.251.

(8) White, E. H. The Chemi and Bioluminescence of Firefly Luciferin : An Efficient Chemical Production of Electronically Excited States. Biooganic 1971, 1 (1-2), 92-122.

(9) McCapra, F. Chemical Mechanisms in Bioluminescence. Acc. Chem. Res. 1976, 9 (6), 201208. https://doi.org/10.1021/ar50102a001.

(10) Mccapra. The Chemistry of Bioluminescence. Proc. R. Soc. Lond. Ser. B 1982, 215, 247-272.

(11) Branchini, B. R.; Murtiashaw, M. H.; Magyar, R. A.; Portier, N. C.; Ruggiero, M. C.; Stroh, J. G. Yellow-Green and Red Firefly Bioluminescence from 5,5-Dimethyloxyluciferin. J. Am. Chem. Soc. 2002, 124 (10), 2112-2113. https://doi.org/10.1021/ja017400m.

(12) Branchini, B. R.; Southworth, T. L.; Fontaine, D. M.; Kohrt, D.; Welcome, F. S.; Florentine, C. M.; Henricks, E. R.; DeBartolo, D. B.; Michelini, E.; Cevenini, L.; Roda, A.; Grossel, M. J. RedEmitting Chimeric Firefly Luciferase for in Vivo Imaging in Low ATP Cellular Environments. Anal. Biochem. 2017, 534, 36-39. https://doi.org/10.1016/j.ab.2017.07.001.

(13) Roura, S.; Gálvez-Montón, C.; Bayes-Genis, A. Bioluminescence Imaging: A Shining Future for Cardiac Regeneration. J. Cell. Mol. Med. 2013, 17 (6), 693-703.

https://doi.org/10.1111/jcmm.12018.

(14) Minekawa, T.; Ohkuma, H.; Abe, K.; Maekawa, H.; Arakawa, H. Practical Application of Bioluminescence Enzyme Immunoassay Using Enhancer for Firefly Luciferin-Luciferase Bioluminescence. Luminescence 2011, 26 (3), 167-171. https://doi.org/10.1002/bio.1200.

(15) Takakura, H.; Kojima, R.; Urano, Y.; Terai, T.; Hanaoka, K.; Nagano, T. Aminoluciferins as Functional Bioluminogenic Substrates of Firefly Luciferase. Chem. - Asian J. 2011, 6 (7), 1800-1810. https://doi.org/10.1002/asia.201000873.

(16) Sun, Y.-Q.; Liu, J.; Wang, P.; Zhang, J.; Guo, W. D-Luciferin Analogues: A Multicolor Toolbox for Bioluminescence Imaging. Angew. Chem. Int. Ed. 2012, 51 (34), 8428-8430. https://doi.org/10.1002/anie.201203565.

(17) Greer, L. F.; Szalay, A. A. Imaging of Light Emission from the Expression of Luciferases in Living Cells and Organisms: A Review. Luminescence 2002, 17 (1), 43-74.

https://doi.org/10.1002/bio.676.

(18) Shinde, R.; Perkins, J.; Contag, C. H. Luciferin Derivatives for Enhanced in Vitro and in Vivo Bioluminescence Assays. Biochemistry 2006, 45 (37), 11103-11112.

https://doi.org/10.1021/bi060475o.

(19) Tian, X.; Li, Z.; Lau, C.; Lu, J. Visualization of in Vivo Hydrogen Sulfide Production by a Bioluminescence Probe in Cancer Cells and Nude Mice. Anal. Chem. 2015, 87 (22), 11325-11331. https://doi.org/10.1021/acs.analchem.5b03712.

(20) Buckley, S. M. K.; Delhove, J. M. K. M.; Perocheau, D. P.; Karda, R.; Rahim, A. A.; Howe, S. J.; Ward, N. J.; Birrell, M. A.; Belvisi, M. G.; Arbuthnot, P.; Johnson, M. R.; Waddington, S. N.; McKay, T. R. In Vivo Bioimaging with Tissue-Specific Transcription Factor Activated Luciferase Reporters. Sci. Rep. 2015, 5 (11842). https://doi.org/10.1038/srep11842. 
(21) Cheng, Y.-Y.; Liu, Y.-J. Theoretical Development of Near-Infrared Bioluminescent Systems. Chem. - Eur. J. 2018, 24 (37), 9340-9352. https://doi.org/10.1002/chem.201800416.

(22) Hiyama, M.; Akiyama, H.; Koga, N. Theoretical Insights into the Effect of PH Values on Oxidation Processes in the Emission of Firefly Luciferin in Aqueous Solution. Luminescence 2017, 32 (6), 1100-1108. https://doi.org/10.1002/bio.3308.

(23) Orlova, G.; Goddard, J. D.; Brovko, L. Yu. Theoretical Study of the Amazing Firefly Bioluminescence: The Formation and Structures of the Light Emitters. J. Am. Chem. Soc. 2003, 125 (23), 6962-6971. https://doi.org/10.1021/ja021255a.

(24) Hosseinkhani, S. Molecular Enigma of Multicolor Bioluminescence of Firefly Luciferase. Cell. Mol. Life Sci. 2011, 68 (7), 1167-1182. https://doi.org/10.1007/s00018-010-0607-0.

(25) Snellenburg, J. J.; Laptenok, S. P.; DeSa, R. J.; Naumov, P.; Solntsev, K. M. Excited-State Dynamics of Oxyluciferin in Firefly Luciferase. J. Am. Chem. Soc. 2016, 138 (50), 16252-16258. https://doi.org/10.1021/jacs.6b05078.

(26) Ran, X. Q.; Zhou, X.; Goddard, J. D. The Spectral-Structural Relationship of a Series of Oxyluciferin Derivatives. ChemPhysChem 2015, 16 (2), 396-402.

https://doi.org/10.1002/cphc.201402611.

(27) Maltsev, O. V.; Nath, N. K.; Naumov, P.; Hintermann, L. Why Is Firefly Oxyluciferin a Notoriously Labile Substance? Angew. Chem. Int. Ed. 2014, 53 (3), 847-850. https://doi.org/10.1002/anie.201307972.

(28) Cheng, Y.-Y.; Liu, Y.-J. What Exactly Is the Light Emitter of a Firefly? J. Chem. Theory Comput. 2015, 11 (11), 5360-5370. https://doi.org/10.1021/acs.jctc.5b00659.

(29) White, E. H.; Wörther, H.; Field, G. F.; McElroy, W. D. Analogs of Firefly Luciferin. J. Org. Chem. 1965, 30 (7), 2344-2348. https://doi.org/10.1021/jo01018a054.

(30) Kakiuchi, M.; Ito, S.; Yamaji, M.; Viviani, V. R.; Maki, S.; Hirano, T. Spectroscopic Properties of Amine-Substituted Analogues of Firefly Luciferin and Oxyluciferin. Photochem. Photobiol. 2017, 93 (2), 486-494. https://doi.org/10.1111/php.12654.

(31) Ghose, A.; Rebarz, M.; Maltsev, O. V.; Hintermann, L.; Ruckebusch, C.; Fron, E.; Hofkens, J.; Mély, Y.; Naumov, P.; Sliwa, M.; Didier, P. Emission Properties of Oxyluciferin and Its Derivatives in Water: Revealing the Nature of the Emissive Species in Firefly Bioluminescence. $J$. Phys. Chem. B 2014, 119 (6), 2638-2649. https://doi.org/10.1021/jp508905m.

(32) Solntsev, K. M.; Laptenok, S. P.; Naumov, P. Photoinduced Dynamics of Oxyluciferin Analogues: Unusual Enol "Super"Photoacidity and Evidence for Keto-Enol Isomerization. J. Am. Chem. Soc. 2012, 134 (40), 16452-16455. https://doi.org/10.1021/ja3045212.

(33) García-Iriepa, C.; Gosset, P.; Berraud-Pache, R.; Zemmouche, M.; Taupier, G.; Dorkenoo, K. D.; Didier, P.; Léonard, J.; Ferré, N.; Navizet, I. Simulation and Analysis of the Spectroscopic Properties of Oxyluciferin and Its Analogues in Water. J. Chem. Theory Comput. 2018, 14 (4), 2117 2126. https://doi.org/10.1021/acs.jctc.7b01240.

(34) Pinto da Silva, L.; Esteves da Silva, J. C. G. Theoretical Study of the Nontraditional EnolBased Photoacidity of Firefly Oxyluciferin. ChemPhysChem 2015, 16 (2), 455-464. https://doi.org/10.1002/cphc.201402533.

(35) Pinto da Silva, L.; Esteves da Silva, J. C. G. Quantum/Molecular Mechanics Study of Firefly Bioluminescence on Luciferase Oxidative Conformation. Chem. Phys. Lett. 2014, 608, 45-49. https://doi.org/10.1016/j.cplett.2014.05.061. 
(36) Pinto da Silva, L.; Simkovitch, R.; Huppert, D.; Esteves da Silva, J. C. G. Theoretical Study of the Efficient Fluorescence Quenching Process of the Firefly Luciferin. J. Photochem. Photobiol. Chem. 2013, 266, 47-54. https://doi.org/10.1016/j.jphotochem.2013.06.001.

(37) Pinto da Silva, L.; Esteves da Silva, J. C. G. Theoretical Analysis of the Color Tuning Mechanism of Oxyluciferin and 5-Hydroxyoxyluciferin. Comput. Theor. Chem. 2012, 988, 56-62. https://doi.org/10.1016/j.comptc.2012.02.029.

(38) Silva, L. P. da; Silva, J. C. G. E. da. Computational Investigation of the Effect of PH on the Color of Firefly Bioluminescence by DFT. ChemPhysChem 2011, 12 (5), 951-960. https://doi.org/10.1002/cphc.201000980.

(39) Chen, S.-F.; Liu, Y.-J.; Navizet, I.; Ferré, N.; Fang, W.-H.; Lindh, R. Systematic Theoretical Investigation on the Light Emitter of Firefly. J. Chem. Theory Comput. 2011, 7 (3), 798-803. https://doi.org/10.1021/ct200045q.

(40) Navizet, I.; Roca-Sanjuán, D.; Yue, L.; Liu, Y.-J.; Ferré, N.; Lindh, R. Are the Bio- and Chemiluminescence States of the Firefly Oxyluciferin the Same as the Fluorescence State? Photochem. Photobiol. 2013, 89 (2), 319-325. https://doi.org/10.1111/php.12007.

(41) Falklöf, O.; Durbeej, B. Distinguishing between Keto-Enol and Acid-Base Forms of Firefly Oxyluciferin through Calculation of Excited-State Equilibrium Constants. J. Comput. Chem. 2014, 35 (30), 2184-2194. https://doi.org/10.1002/jcc.23735.

(42) Rebarz, M.; Kukovec, B.-M.; Maltsev, O. V.; Ruckebusch, C.; Hintermann, L.; Naumov, P.; Sliwa, M. Deciphering the Protonation and Tautomeric Equilibria of Firefly Oxyluciferin by Molecular Engineering and Multivariate Curve Resolution. Chem. Sci. 2013, 4 (10), 3803-3809. https://doi.org/10.1039/c3sc50715g.

(43) Hirano, T.; Hasumi, Y.; Ohtsuka, K.; Maki, S.; Niwa, H.; Yamaji, M.; Hashizume, D. Spectroscopic Studies of the Light-Color Modulation Mechanism of Firefly (Beetle) Bioluminescence. J. Am. Chem. Soc. 2009, 131 (6), 2385-2396. https://doi.org/10.1021/ja808836b.

(44) Presiado, I.; Erez, Y.; Simkovitch, R.; Shomer, S.; Gepshtein, R.; Pinto da Silva, L.; Esteves da Silva, J. C. G.; Huppert, D. Excited-State Proton Transfer of Firefly Dehydroluciferin. J. Phys. Chem. A 2012, 116 (44), 10770-10779. https://doi.org/10.1021/jp308818r.

(45) Erez, Y.; Presiado, I.; Gepshtein, R.; Pinto da Silva, L.; Esteves da Silva, J. C. G.; Huppert, D. Comparative Study of the Photoprotolytic Reactions of D-Luciferin and Oxyluciferin. J. Phys. Chem. A 2012, 116 (28), 7452-7461. https://doi.org/10.1021/jp301910p.

(46) Presiado, I.; Erez, Y.; Huppert, D. Excited-State Intermolecular Proton Transfer of Firefly Luciferin III. Proton Transfer to a Mild Base. J. Phys. Chem. A 2010, 114 (51), 13337-13346. https://doi.org/10.1021/jp107360d.

(47) Erez, Y.; Presiado, I.; Gepshtein, R.; Huppert, D. Excited-State Intermolecular Proton Transfer of Firefly Luciferin IV. Temperature and PH Dependence. J. Phys. Chem. A 2011, 115 (9), $1617-$ 1626. https://doi.org/10.1021/jp110889v.

(48) Cherednikova, E. Y.; Chikishev, A. Y.; Kosobokova, O. V.; Mizuno, M.; Sakai, M.; Takahashi, H. Picosecond Time-Resolved Absorption Spectroscopy of Luciferin. Chem. Phys. Lett. 1999, 308 (5-6), 369-372. https://doi.org/10.1016/S0009-2614(99)00625-9.

(49) Pinto da Silva, L.; Esteves da Silva, J. C. G. Chemiexcitation Induced Proton Transfer: Enolate Oxyluciferin as the Firefly Bioluminophore. J. Phys. Chem. B 2015, 119 (6), 2140-2148. https://doi.org/10.1021/jp5036458. 
(50) Pinto da Silva, L.; Simkovitch, R.; Huppert, D.; Esteves da Silva, J. C. G. Oxyluciferin Photoacidity: The Missing Element for Solving the Keto-Enol Mystery? ChemPhysChem 2013, 14 (15), 3441-3446. https://doi.org/10.1002/cphc.201300402.

(51) Pinto da Silva, L.; Santos, A. J. M.; Esteves da Silva, J. C. G. Efficient Firefly Chemi/Bioluminescence: Evidence for Chemiexcitation Resulting from the Decomposition of a Neutral Firefly Dioxetanone Molecule. J. Phys. Chem. A 2013, 117 (1), 94-100. https://doi.org/10.1021/jp311711p.

(52) Silva, L. P. da; Silva, J. C. G. E. da. Firefly Chemiluminescence and Bioluminescence: Efficient Generation of Excited States. ChemPhysChem 2012, 13 (9), 2257-2262.

https://doi.org/10.1002/cphc.201200195. 